\title{
EL YESO, UN MATERIAL APROPIADO PARA UNA CONSTRUCCION BARATA
}

\author{
(GYPSUM, AN APPROPRIATE MATERIAL FOR LOW COST HOUSING)
}

Marc Nolhier: Plan de Construcción, Francia Traducción y adaptación: Julia Mallart IETcc/CSIC

RESUMEN

En este artículo se hace una valoración de las propiedades del yeso en cuanto a resistencia, trabajabilidad y bajo costo con el fin de aplicarlo a una construcción de viviendas baratas en paises poco desarrollados.

Basándose en experimentos llevados a cabo en países africanos, se estudia el problema de tecnología, de la adaptación de la mano de obra al proceso de construcción con bloques de yeso prefabricados y de su rentabilidad.
SUMMARY

This work presents an evaluation of the lime resistance, workability properties and low cost, applied to low cost housing in developping countries.

Starting from the experiences carried out in African countries, the technical problems, labour adaptation to the construction process with gypsum prefabricated blocks and its profitability are studied.

\section{INTRODUCCION}

Desde 1982 se desarrollan en Francia y en varios paises africanos y dentro del marco del programa REXCOOP, acciones de investigación y de experimentación para una construcción barata a base de yeso: "Realizaciones Experimentales en Cooperación".

Nutridas por la observación de una tradición milenaria de construcción que utiliza el yeso, reforzadas por los resultados de investigación y experimentación llevados a cabo a mediados de este siglo en Argelia, Alemania y Francia, estas acciones interesan principalmente a los paises cálidos y secos y se han aplicado ya en Senegal y Túnez.

Después de un año de trabajo, es posible aportar elementos de respuesta sobre el interés de este material para una construcción barata en los paises en desarrollo.

Esta comunicación presenta la actualidad técnica de este tipo de construcción, y tras proponer criterios de definición de las técnicas apropiadas, hace la evaluación de una técnica de utilización del yeso en función de estos criterios.

\section{TECNICAS PROMETEDORAS}

2.1. El yeso es el resultado de la cocción, a temperatura moderada, de la roca de yeso o sulfato de calcio bihidratado. Los yesos son materiales complejos ya que según la temperatura y las condiciones de cocción, es posible obtener diferentes tipos de productos. De tal forma, el yeso artesanal, preparado sin precauciones especiales, es una mezcla de variedades diferentes y sus calidades son irregulares. Asi pues, las técnicas modernas de cocción industrial permiten obtener una u otra variedad que corresponde a usos específicos: yeso de construcción, negro y blanco; escayola de gran dureza; yeso de enlucir, para proyección, para revoco exterior, para usos médicos, para la prefabricación, etc...

Amasado con agua, el yeso se rehidrata, fragua con rapidez, cristaliza y se endurece para dar un sulfato de calcio bihidratado semejante al yeso inicial: $\mathrm{Ca}$ SO4. $2 \mathrm{H}_{2} \mathrm{O}$.

Antaño, en muchos países, se utilizaba el yeso tanto en el interior como en el exterior de los edificios para obra y terminaciones. En la actualidad se utiliza principalmente para terminaciones interiores (enlucido de tabiques y techos) o bien 

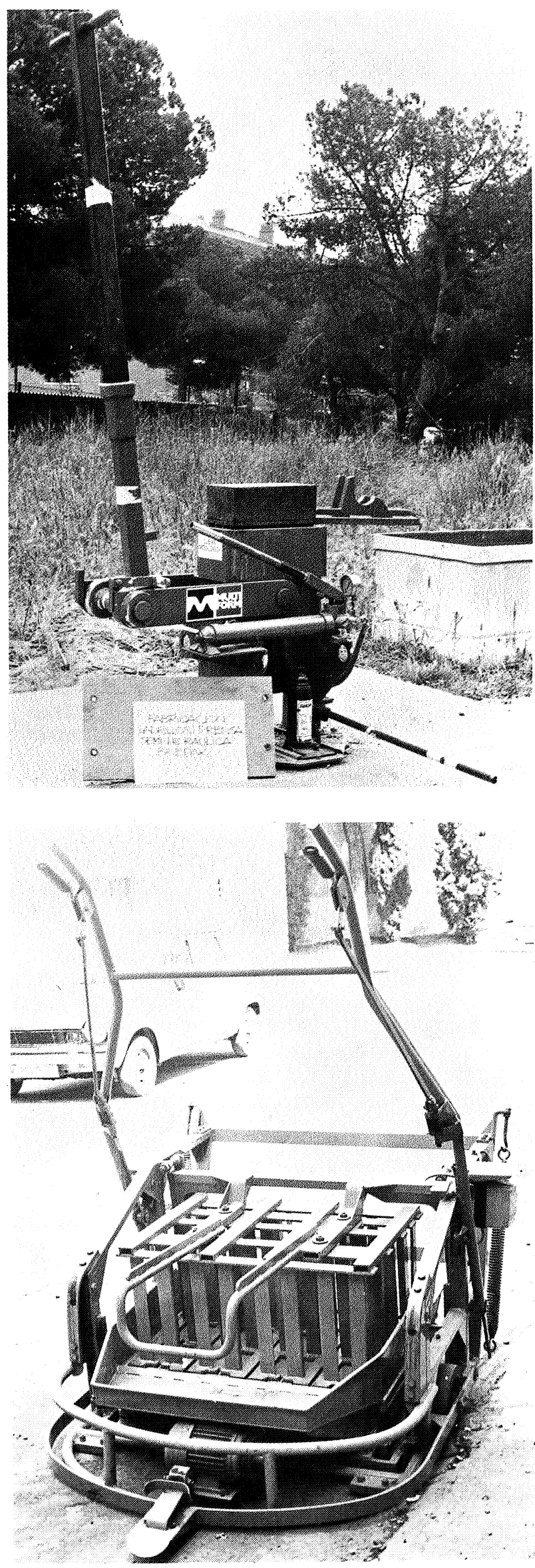

Máquinas para la producción de bloques de yeso. IETCC.

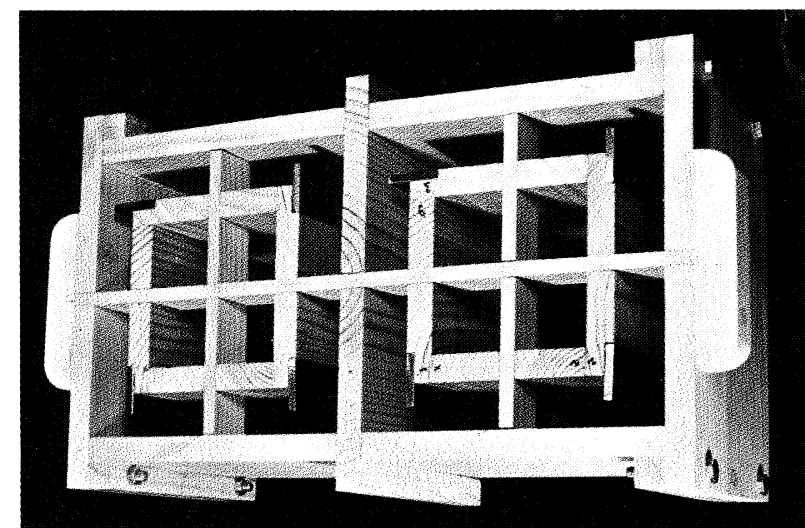

Molde en madera para bloque alveolar de yeso.

en forma de elementos prefabricados (elementos de tabicado y de techo, planchas de paramento).

Este uso moderno se ha hecho ya clásico en muchos paises industrializados. En esta comunicación no nos ocuparemos más que de la utilización del yeso en obra gruesa, principalmente en muros verticales.

2.2. El yeso ha sido utilizado masivamente como elemento constructivo en obra de muros, de carga o no, con prácticamente todas las técnicas: bloques de cascote, proyección mecanizada, elementos prefabricados de todo tamaño, planchas delgadas encartonadas o simple relleno de muros con armadura de madera.

Parece que dos procedimientos deberán gozar del privilegio del P.E.D. para llevar a cabo una construcción barata: los pequeños bloques y el sistema de tapiales.

Por medio de moldeado o de extrusión es posible realizar prácticamente todas las formas de pequeños bloques de yeso macizos o huecos. Según la granulometria del material y la precisión de los moldes se obtendrán bloques más o menos bastos. Un fácil colado de la mezcla yesoagua, su velocidad de fraguado y la facilidad con que se obtienen productos de superficie perfecta favorecen la fabricación de bloques con buena precisión dimensional $(0,1 \mathrm{~mm})$ que portan espigas, mortajas y dos caras lisas. Estos bloques se colocan pegados y no necesitan más que una capa de enlucido. Según la presencia o no de áridos (yeso o arena), y según las formas (macizas o huecas), se obtiene fácilmente compuestos que presentan resistencias superiores a 50 $\mathrm{kg} / \mathrm{cm}^{2}$ a compresión. En la actualidad se utilizan en Senegal, canales alveolados de $60 \times 40 \times 15$ para la fabricación de muros de carga $\left(4\right.$ por $\left.\mathrm{M}^{4}\right)$. 

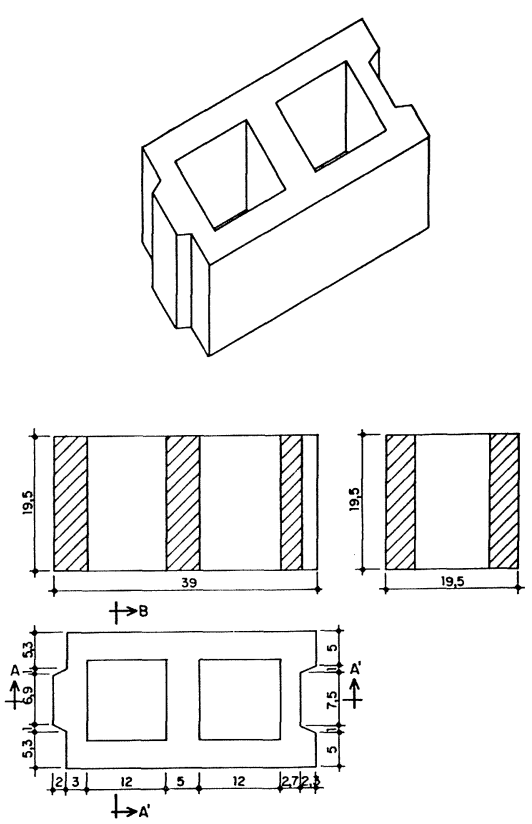

Diseño de bloques de yeso. IETcc.

Esta forma de utilización del yeso no es rentable más que con una producción de calidad mantenida y necesida una unidad industrial (que puede no ser muy sofisticada).

A la inversa, si el yeso está fabricado en una instalación artesanal muy primitiva se impone la técnica del tapial por sucesivas tongadas. El yeso basto producido de esta forma, mezcla irregular de semihidrato, recocido o sin cocer, se utiliza como argamasa de un hormigón de gránulos que pueden ser yesosos. Este sistema de obra utiliza la ADAUA en Nouakchott (Mauritania) para construir un centenar de viviendas baratas.

Se utilizan igualmente otras técnicas para la confección de cubiertas. Citemos las cúpulas de yeso proyectado sobre un molde de paliester, construidas en DAKAR, con formas redondas inspiradas en la arquitectura clásica en Mauritania, de bloques de yeso y cascote. Estas últimas construcciones plantean árduos problemas técnicos de utilización del yeso en exteriores: la resistencia al agua.

2.3. El principal inconveniente del yeso es sin duda alguna su sensibilidad al agua. Un litro de agua dulce puede disolver dos gramos de yeso. La humedad ambiente no provoca, en si misma, daños estructurales, pero puede favorecer el desarrollo de microorganismos. Por consiguiente, las reglas de arte de los paises nórdicos prescriben evitar el yeso donde haya goteo regular ya que indefectiblemente acarrea pérdidas del material por erosión. Naturalmente, el clima en los paises cálidos permite otras prescripciones.

En primer lugar, es posible concebir un muro doble en el que la parte portadora de yeso quede en el interior y protegida por un fino tabique protector. Estas técnicas no parecen precisamente adaptarse a la construcción de bajo precio, sin embargo pueden resolver ciertos problemas de aislamiento térmico en edificios más caros.

La segunda solución consiste en proteger directamente el yeso con una pintura, revoco o revestimiento. Las técnicas de revestimiento con una capa fina de pintura o enlucido (aceite de lino hirviendo, cal...) nos parecen adaptarse bien. En cuanto a los enlucidos tenemos tres opciones: las pinturas plásticas espesas, los enlucidos a base de yeso hidrofugado, los antiguos enlucidos a base de yeso, de cal y de arena.

Podemos desconsiderar los primeros. En general son muy eficaces pero siendo de importación en su totalidad, su precio de venta es incompatible con una construcción barata. Es preferible aconsejar el uso de la tercera categoria de revestimientos inspirada en revestimientos tradicionales parisinos a base de yeso graso, que durante mucho tiempo han dado plena satisfacción.

La tercera solución y sin duda la más interesante consiste en dejar el yeso desnudo y optar por dispositivos arquitecturales susceptibles de preservarlo del goteo de agua: voladizos, canalones, franja estanca a nivel del suelo, basamentos de cemento elevados, etc...

La realización más ilustrativa dentro de esta concepción es la quesería del monasterio de Keur Moussa construida cerca de Dakar con placas de yeso sin protección. Este edificio lleva resistiendo seis años, sin daños aparentes, a una higrometría interior muy elevada (elaboración de quesos) y a las lluvias estacionales ( 575 $\mathrm{mm} / \mathrm{año}$ ).

\section{3. ¿QUE ADECUACION?}

Después de haber trillado el panorama de las técnicas de utilización del yeso más prometedoras para construcciones de bajo precio en P.E.D., conviene definir las condiciones de una buena adecuación a estas técnicas.

3.1. Se afrontan diferentes definiciones de las tecnologias apropiadas. Daniel BIAU a propuesto en el coloquio internacional M.T.C. celebrado en UNESCO en enero de 1983, la clasificación que adoptaremos y que resumimos a continuación.

Los criterios quedan agrupados en dos categorias, aquellos que se refieren a la oferta, y los que conciernen a la demanda.

En relación con la oferta, hay que distinguir por una parte los recursos disponibles y por otra los intereses que intervienen en la producción del hábitat: 
- Referente a recursos (humanos-empleos, calificaciones-materiales-minas, energias, equipos de producción, de transporte, de obra) se distingue generalmente entre local e importado.

- En cuanto a los intereses que intervienen, está claro, por una parte, que no todos tienen la misma estrategia y por otra parte que no se puede desarrollar una tecnología en tanto no haya despertado el interés de personas de economia suficientemente fuerte. Se distingue a los productores directos (obreros, destajistas) que intentan aumentar su salario, los ejecutivos (contratistas, fabricantes, empresarios) cuyo fin es rentabilizar sus inversiones y los poderes públicos que actúan en distintos niveles (hipotecarios, fiscales...).

En cuanto a la demanda, se distingue entre recursos (solvencia) y aspiraciones (disponer de un hábitat duradero, confortable, adaptado al modo de vivir...) de los distintos grupos sociales.

Una vez enunciados con claridad, se deben ponderar estos criterios según el contexto. Nos proponemos llevarlo a cabo con el ejemplo de la construcción de muros de carga con bloques de yeso.

3.2. a) En lo concerniente a recursos humanos hay que distinguir la producción del polvo, la fabricación de los bloques y la mano de obra (una o dos personas por tonelada de producción anual) pero esta deberá ser cualificada de modo que la gerencia de la instalación industrial sea correcta.

Por su parte, la fabricación de bloques de una regularidad perfecta (calidad y dimensión) puede efectuarse, como en Senegal, en un taller artesanal con un consumo alto de mano de obra $\left(20 \mathrm{~m}^{2} /\right.$ Hombre/Día para bloques de $\left.15 \mathrm{~cm}\right) \mathrm{de}$ baja cualificación (sólo unos dias de formación para un peón).

En fin, la tecnologia de colocación de los bloques de yeso está ligada a la albañileria tradicional: es una gran consumidora de mano de obra de baja cualificación pero presenta una productividad superior a la de la colocación de perpiaños de cemento (el 30 por ciento). Esta tecnologia se acepta bien en países de albañiles. Sin embargo, se considera preferible formar instaladores a partir de obreros no cualificados mejor que a partir de albañiles que olvidan con dificultad los gestos tradicionales de colocación de bloques (el albañil rellena una junta ancha mientras que el yesero nivela juntas estrechas con martillo y calzo).

Resumiendo, se trata de una tecnologia que globalmente ocupa mucha mano de obra de una cualificación que abunda en los paises africanos.

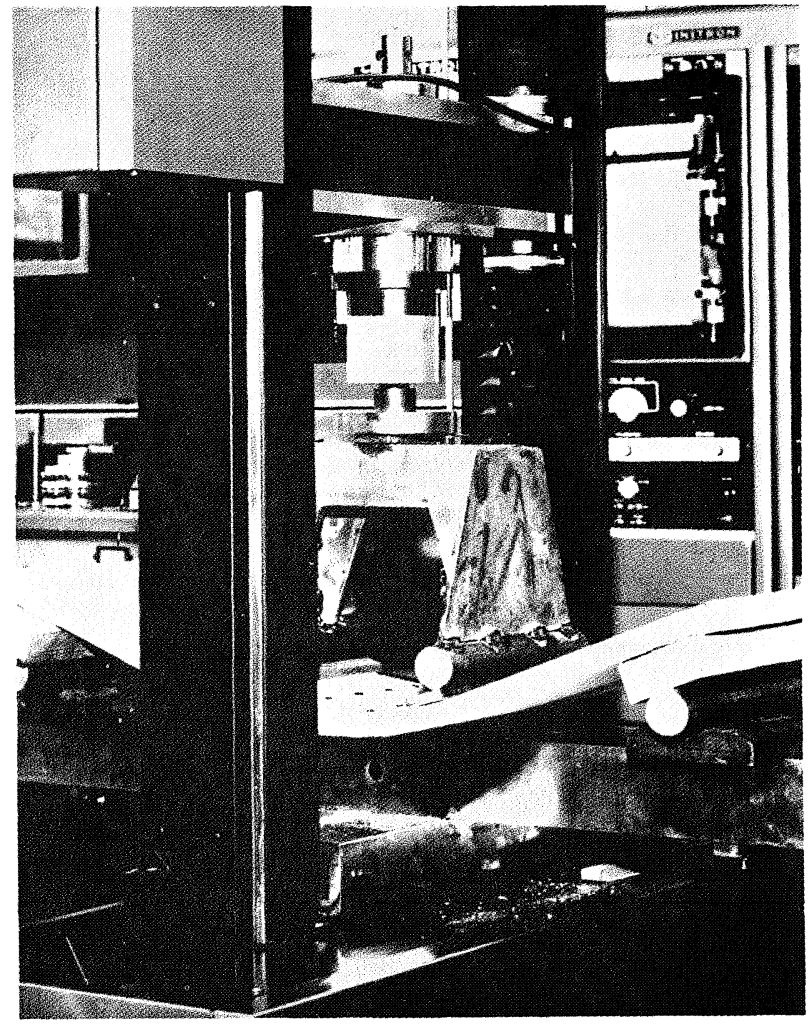

Analisis estructural en laboratorio de paneles de yeso con fibras.
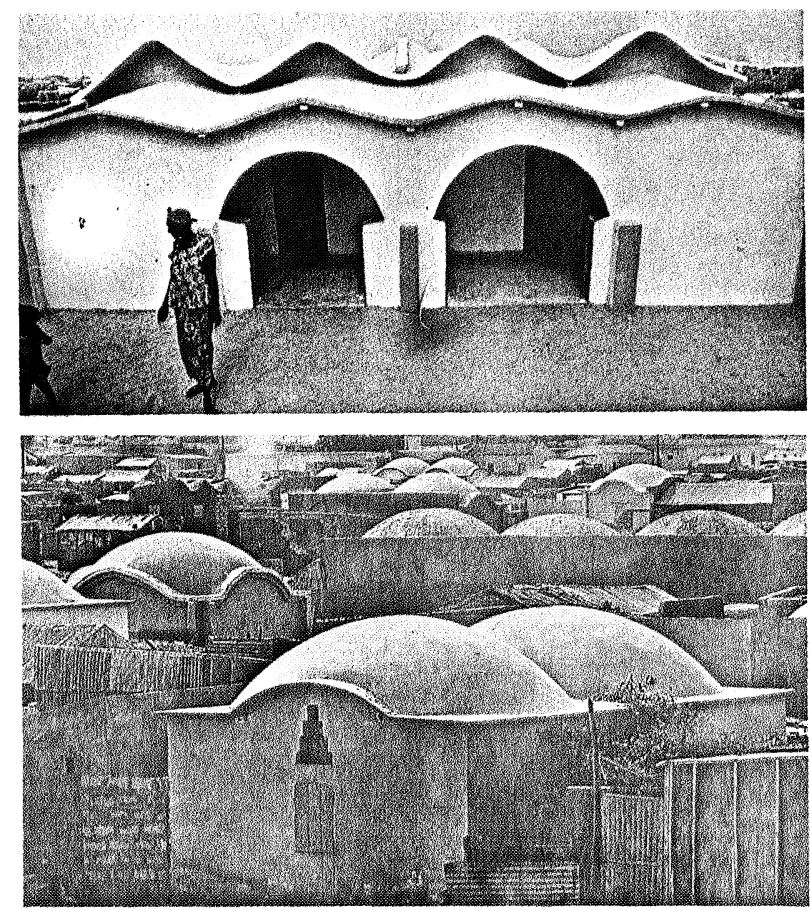

La construccion con yeso permite gran libertad de formas.

3.2. b) En cuanto a recursos materiales se distingue la disponibilidad de materias, de energia y de equipos.

El yeso que se utiliza para la prefabricación puede ser de origen natural y de origen industrial. 
Los paises de clima cálido y seco están, en general, bien provistos de yeso, de filón o eólico. En Africa podemos citar: Mauritania, Marruecos, Argelia, Túnez, Egipto, Sudán, etc. Otros paises de esta misma zona disponen de industrias de transformación de los fosfatos en abonos cuyo principal subproducto en el fosfoyeso, en el caso de Senegal y de Marruecos.

A la inversa, el fuel y la electricidad necesarios para la cocción del yeso y para la fabricación de los bloques son generalmente caros en divisas. Hay que subrayar que en comparación con cales y cementos, la producción de yeso exige poca energia $(64,5 \mathrm{~kg}$ fuel/t para la yeseria senegalesa de 25.000 t/año en comparación de los 159 $\mathrm{kg}$ fuel/t para la cemetera dakaresa de 380.000 t/año). Además, la baja temperatura requerida (120 grados) puede hacer que resulte interesante la utilización de la energia solar (experiencia en curso en Mauritania). Aun cuando el material no es energéticamente gratuito, su utilización masiva puede resultar interesante. En Senegal se han comparado los costos energéticos de los tabiques de planchas de yeso alveolado y de tabiques de aglomerados de cemento. En $7 \mathrm{~cm}$ de grosor, el aglomerado consume $5 \mathrm{~kg}$ de fuel $/ \mathrm{m}$, la plancha 3,1 , en $10 \mathrm{~cm}$ el aglomerado consume $6,2 \mathrm{~kg} / \mathrm{m}^{2}$ y la plancha 4,2 . Este ahorro de 32 a 28 por ciento se debe principalmente al ahorro de revestimiento autorizado por el bloque de yeso con superficie perfectamente terminada.

En fin, en lo que concierne a equipos de cocción, de prefabricación, de transporte y de obra, se constata con facilidad que aun cuando sean relativamente poco sofisticados, los hornos, los moldes y los materiales de manutención serán casi sistemáticamente importados de los países industrializados. Su mantenimiento, sin embargo, no necesita generalmente especialistas foráneos.

Se debe examinar, caso por caso y según su localización, el criterio relativo a urecursos materiales", el tamaño de la instalación y el sistema constructivo programado. Si existen recursos naturales 0 artificiales de yeso, será pertinente valorarlos. En caso contrario, y a pesar de los precios granel especialmente ventajosos, es probable que el bloque de yeso no se desarrolle.

3.2. c) Relativo a las estrategias de las personas que intervienen en la producción del hábitat, existen intereses varios -los de obreros, los de Estado y los del empresario- que se conjugan y se oponen.

Hemos mencionado lo interesante de formar obreros que no hayan ejercido anteriormente el oficio de albañil. Estos serán los promotores del nuevo material. Sentirán la oposición al cambio que ejercerán otras corporaciones de oficios que deberán adaptarse a los imperativos de una nue- va tecnologia que tolera mal el más o menos. Sería pues deseable que todos los trabajos de hormigonera quedasen concluidos antes de empezar a colocar los primeros bloques de yeso, con el fin de que la obra sea más una obra de ensamblaje de componentes terminados que un gigantesco trabajo de bricolage recompuesto por fin con una capa gorda de revestimiento, como ocurre con frecuencia.

Los empresarios de obra deberán igualmente el planning de su obra, la contrata de personal y el precio de coste aceptando comprar componentes elaborados de mejor rendimiento aunque más caros, cambios éstos que supondrán otros tantos frenos a la innovación.

A la inversa, los industriales productores de polvo y de componentes tendrán que optimizar la rentabilidad de la inversión y de los gastos fijos significativos de funcionamiento (alrededor de 8 millones de Francos en 10 años por la unidad de 25.000 t/año de DAKAR) luchando en dura competencia con los monopolios de perpiaños de cemento. Se puede conquistar una parte del mercado de la construcción según diferentes estrategias que privilegien tal o tal otro producto a base de yeso. Asi pues, en Senegal el empresario productor eleva los precios del polvo, de yeso para staff, del yeso para proyectar, de las planchas de techo, con el fin de competir con productos equivalentes (importados o a base de cemento) y vende las planchas y los bloques prácticamente a precio de coste. Esta compensación de gastos de amortización va dirigida a favorecer al máximo el bloque de yeso para efectuar su lanzamiento en el mercado.

Pero dentro de los mismos poderes públicos se enfrentan diferentes razonamientos. La disminución de los costos de construcción de igual calidad recomendada por los ministerios que tienen a su cargo la construcción se apoyan casi siempre en la racionalización de las técnicas convencionales a base de cemento, mientras que la rentabilización del potencial de las industrias y materiales nacionales, el ahorro de energía y de divisas corre a cargo de los ministerios de industria y de hacienda.

3.3. Concerniente a demanda en su doble aspecto de solvencia y exigencias cualitativas, los primeros criterios que afecten a un procedimiento innovador como el muro de carga con bloques de yeso son los que la maestría de obras públicas decreta. En efecto, en primer lugar el sector informal de la autoconstrucción no hará suyo un procedimiento que no tenga sólidas realizaciones de referencia; luego, la maestria de obras públicas es a menudo el único intérprete explicito de las aspiraciones populares y por último, es quizás el único promotor que aceptará cargar con los riesgos de la técnica y de su aceptabilidad. 

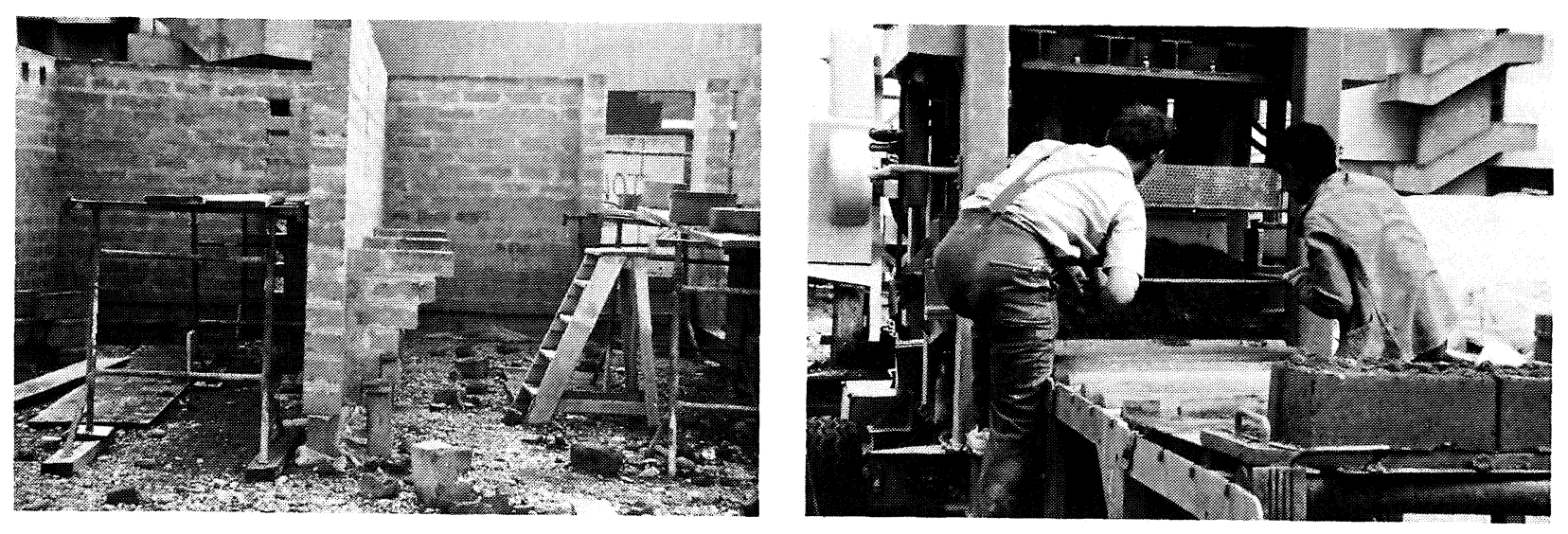

Investigación aplicada, producción y ejecución de muros de bloques de yeso.

El criterio de solvencia ha sido parcialmente demostrado, por ejemplo en Senegal, donde edificios públicos y viviendas han sido construidos con bloques de yeso con un coste comparable al de las viviendas sociales que se construyen habitualmente $\left(1.000 \mathrm{~F} / \mathrm{m}^{2}\right)$. Pero es necesario confirmar estas experiencias en mayor escala y en condiciones realmente competitivas.

La aspiración de alcanzar un hábitat confortable se colma con creces con las calidades unánimemente reconocidas del yeso como son el aislamiento, la regulación higrométrica, la resistencia al fuego, la trabajabilidad en obras decorativas y estéticas.

Para terminar diremos que las tecnologias que acabamos de presentar colman las aspiraciones de un hábitat resistente al tiempo y al agua; la investigación y la experimentación tienden a mejorar la relación calidad/precio de esta función.

\section{CONCLUSION}

Naturalmente es difícil formular recomendaciones precisas y exhaustivas a partir de las consi- deraciones antedichas. Sin embargo, si existe la disponibilidad de yeso natural o químico y si hay inversores y en cuanto los poderes públicos apoyen medianamente la promoción del yeso, es decir, si existe un potencial real de oferta, será interesante intentar la experiencia. A ella se aplican en la actualidad senegaleses y tunecinos.

Está claro que no se puede certificar el interés de este tipo de tecnologia que presentamos únicamente por medio de estudios de laboratorio y de factibilidad. Sólo una experimentación a nivel significativo y en la que entren en juego todos los actores del mundo de la construcción podrá desatascar los frenos sucesivos que traban a la innovación y permitir evaluar el porvenir de un material y de una técnica.

Ya que se pide, y con razón, que los investigadores salgan de sus laboratorios para enfrentarse a prácticas concretas; hay que pedir igualmente medios para la valorización y desarrollo de la investigación, y los responsables politicos habrán de tener conciencia de la necesidad de lanzar programas de experimentación a gran escala. 